\title{
Prevalence and Predisposing Factors Associated with Facial and Dentoalveolar Trauma Among Children and Adolescents Aged Between 06 Months and 15 Years Having Consulted Casablanca Dental Emergency Department
}

\author{
Loubna Benkirane ${ }^{1}$ Noura Targhaline ${ }^{2}$ Mouna Hamza' Samira El Arabi ${ }^{1}$
}

'Pediatric Dentistry Department, Faculty of Dentistry of Casablanca, Hassan II University of Casablanca, Casablanca, Morocco

${ }^{2}$ Private Practice, Casablanca, Morocco
Address for correspondence: Loubna Benkirane, Pediatric Dentistry Department, Faculty of Dentistry of Casablanca, Hassan II University of Casablanca, Casablanca 20000, Morocco

E-mail: loubna.loubnabenkirane.benkira@gmail.com

\begin{abstract}
Objective: The present study aimed to determine the sociodemographic profiles, the injury circumstances, the clinical data, and the immediate management of traumatic dental injuries (TDI) in children and adolescents attending the only public dental emergency service in Casablanca.

Materials and Methods: A cross-sectional study was conducted among children and adolescents, aged between 6 months and 15 years, who consulted the Casablanca dental emergency department between January and April 2019. The data obtained from questionnaires by a calibrated interviewer were collected and analyzed by using SPSS IBM.

Results: The results showed a prevalence of $18.1 \%$ of TDI with a sex ratio of 2.5 in favor of boys, a mean age of the participants was $10.1 \pm 2.9$ years. The 9- to 12-year-old group was the most affected (41.2\%). The street was the main place where the trauma occurred (47.3\%). Meanwhile, accidental falls were the predominant reported etiology (59.5\%). The percentage of patients who consulted on the day of the trauma was $36.6 \%$, and $40.4 \%$ of children consulted the dental emergency service as a second line. The prevalence of permanent teeth affected was $75.9 \%$. In the primary dentition, the most frequent type of trauma was avulsion, while in permanent dentition, uncomplicated crown fractures were predominant.

Concerning the management of trauma, 6 out of 11 avulsed teeth were re-implanted, and only 9 out of 77 coronal fragments were picked up at the site of the trauma.

Conclusion: Considering the prevalence of $18.1 \%$ of TDI in children and the high percentage of falls and traffic accidents as common causes, the level of social awareness and knowledge of the importance of emergency intervention immediately following dental trauma should be increased.
\end{abstract}

Keywords: Adolescent, children, emergency service, overjet, traumatic dental injuries

How to cite this article: Benkirane L, Targhaline N, Hamza M, El Arabi S. Prevalence and Predisposing Factors Associated with Facial and Dentoalveolar Trauma Among Children and Adolescents Aged Between 06 Months and 15 Years Having Consulted Casablanca Dental Emergency Department.. J Pediatr Dent 2021;7(1):00-00

OPEN ACCESS This work is licensed under a Creative Commons Attribution-NonCommercial 4.0 International License. 


\section{Introduction}

Alongside dental caries, which is a real public health problem and a source of disparities between different social strata, increasing attention has been paid for years to dental trauma. It is not a disease but a consequence of several unavoidable risk factors in life. Several studies have shown a substantial increase in dental trauma over the last few decades, particularly among children and adolescents.[1] Other studies reveal that dental injuries are one of the most frequent reasons behind emergency consultations. [2,3]

The literature shows that most traumatized teeth are both primary and permanent upper maxillary incisors. [4] Uncomplicated crown fractures in the permanent dentition are the most common type of injury when luxation injuries occurred more frequently in the primary dentition.[5] After trauma to primary incisors, it is essential to consider the possible risks of sequelae in successor teeth due to the close relationship between the apex of the primary tooth and the development of the permanent successor. The types of trauma that most affect the permanent successors are intrusion and avulsion of the primary tooth.[6]

As dental trauma is unpredictable, it is difficult to accurately determine the prognosis of injuries. They can result in tooth loss and/or severe aesthetic, functional, social, economic damage and can have a psychological impact and influence the quality of life. They, therefore, pose a real threat to children and their families.[7]

Patients with dental trauma need to be aware that certain injuries require multiple appointments and/or subsequent reviews over time. Success depends on several parameters; some are specific to the conditions of the trauma, such as consultation time, others are specific to the child such as the age and the degree of cooperation, others are specific to the tooth, including the stage of maturation and the size of pulpal exposure.

The ultimate goal is to minimize undesirable complications and achieve favorable survival rates for traumatized teeth.

The International Association of Dental Traumatology (IADT) [8,9] issued recommendations to guide and assist in the care management of dental trauma in both primary and permanent dentition.

Although multiples report in the literature state that the types of dental trauma are similar in the populations, it is imperative that each community analyze the data for specific recommendations concerning prevention and management.
In Casablanca, there is a paucity of epidemiological data regarding dental injuries in children and adolescents. The first investigation regarding the characteristic of dental trauma in children and adolescents was done in 1997 in the pediatric dentistry department of the Dental Consultation and Treatment Centre (CCTD), but it wasn't published.

The aim of this study was to evaluate the prevalence of dental injuries, etiology, circumstances of its occurrence, types of TDI, treatment in children and adolescents who referred to the Dental Consultation and Emergency Department (SCUD) affiliated to the CCTD of Casablanca.

\section{Materials and Methods}

This is a descriptive prospective study of all trauma children and adolescents aged between 06 months and 15 years who presented to the SCUD of Casablanca for TDI, over a period of 3 months from January to April 2019, including patients referred from other hospitals. Children already treated for dental trauma as well as children with special needs, were excluded from the study.

The research protocol was approved by the Ethics Committee of the Casablanca Faculty of Dentistry. Prior access, a permission was granted from the Casablanca Dental Consultation and Treatment Centre and from the Emergency Department.

Before filling out the questionnaire and starting the pre-investigation and the actual investigation, verbal and written consent from parents was obtained to clarify the steps and tools of the examination and show that it is voluntary, and that the data will be kept confidential.

One investigator has trained under the supervision of a professor of pediatric dentistry for the collection of information used in the study. The questionnaire to be filled has consisted of four parts dealing successively with the sociodemographic data, the etiology, the circumstances of the trauma, the type of the trauma (according to Andreasen's classification,[10] and the different emergency treatments carried out.

After a brief and concise anamnesis, a clinical and radiographic examination was carried out and the diagnosis was confirmed - by the assigned pedodontist when the shift took place during the week or by the interns or residents on call at weekends, who directly handled or delegated the patients' treatment to the practitioners of the shift.

\section{Statistical analysis}

Data analysis was performed using IBM SPSS Statistics (Version 20.0. Armonk, NY: IBM Corp, USA) for 
Windows and included descriptive statistics of different variables with univariate analysis. Statistical significance for the association between age, location, etiology and types of traumas was determined using Pearson chisquared test. The level of significance was set at $5 \%$.

\section{Results}

The survey revealed that 131 (18.1\%) among the 725 patients aged below 15 years, who visited the SCUD during the study period, had consulted for oral trauma. Odontogenic infectious related to caries and pulpal pain represented respectively $44.7 \%$ and $32.4 \%$.

The average age of our patients was $10.1 \pm 2.9$ years. The distribution of traumatized children according to sociodemographic variables is shown in Table 1.

Patients who consulted the same day were of the order of $36.6 \%, 27.5 \%$ did it between the first and the seventh day and $36 \%$ had consulted within more than a week after.

Table 1. Distribution of TDI according to sociodemographic variables

\begin{tabular}{|c|c|c|}
\hline Variables & $\mathbf{n}$ & $\%$ \\
\hline \multicolumn{3}{|l|}{ Groups' Age } \\
\hline$\leq$ to 3 years & 13 & 9.9 \\
\hline $3-6$ years & 9 & 6.9 \\
\hline $6-9$ years & 21 & 16 \\
\hline $9-12$ years & 54 & 41.2 \\
\hline $12-15$ years & 34 & 26 \\
\hline \multicolumn{3}{|l|}{ Gender } \\
\hline Males & 94 & 71.8 \\
\hline Females & 37 & 28.2 \\
\hline \multicolumn{3}{|l|}{ Level of parental education } \\
\hline None & 17 & 13 \\
\hline Primary & 51 & 38.9 \\
\hline Secondary & 43 & 32.8 \\
\hline Academic & 20 & 15.3 \\
\hline \multicolumn{3}{|l|}{ RAMED* coverage } \\
\hline Patients with RAMED & 121 & 92.4 \\
\hline Patients paying for care & 10 & 76 \\
\hline \multicolumn{3}{|l|}{ Living area } \\
\hline Urban & 131 & 100 \\
\hline Rural & 0 & 0 \\
\hline Total & 131 & 100 \\
\hline \multicolumn{3}{|c|}{$\begin{array}{l}\text { RAMED*: This free medical assistance is based on the principles of national } \\
\text { solidarity for the needy benefit. Moroccan public health structures take full } \\
\text { responsibility for a basket of care including urgent care provided in the } \\
\text { context of dental trauma. Patients who do not have access to such a free } \\
\text { medical care are the paying ones }\end{array}$} \\
\hline
\end{tabular}

The street was the most frequent site of trauma occurrence for both sexes, mainly in boys with $53.2 \%$ vs $32.5 \%$ for girls. Concerning the etiologies of trauma, falls were by far the most frequent regardless of gender with $56.4 \%$ for boys and $67.6 \%$ for girls.

The distribution of the location and etiologies of trauma by age is presented in Table 2 .

Regarding the place of the first consultation following the trauma occurrence, we found that among the $40.4 \%$ of the patients who did not consult the SCUD directly; $26.7 \%$ of them consulted a specialist doctor and the remaining (13.7\%) consulted a dentist in the liberal sector without immediate care. The reasons given by the parents were related to the lack of cooperation from children (44.4\%), the lack of radiography (38.9\%) or the lack of equipment (16.7\%).

The facial lesions identified represented $23.7 \%$ and were mainly localized on the upper lip. In addition to 3 patients who had a nasal fracture which were referred by the maxillofacial surgery department of the hospital on August 20 for the management of the dental emergency.

The permanent dentition was the most affected. That is, among the 253 teeth involved, 192 (75.9\%) had permanent dentition. Within this percentage, 139 teeth were mature, and 53 were immature.

The distribution by type of traumatized teeth is shown in Table 3. Concerning the number of traumatized teeth, the total number of traumatized teeth was 253 .

In 51 patients $(38.9 \%)$, only one tooth was affected, $57(43.5 \%)$ of the patients presented two traumatized teeth, 11 had three, and 12 had four or more traumatized teeth. The damage of two teeth was mainly related to public road accidents (62.5\%) and violence (56.5\%).

Concerning the type of trauma, hard tissue trauma represented $55.1 \%$ while periodontal tissue trauma represented $43 \%$. The trauma associating hard tissue and periodontal tissues concerned $13.7 \%$ of the patients mainly the 6 to 9 years old and the 12-15 years old with respectively $19 \%$ and $20.6 \%$. Avulsion was the most common type of injury to the periodontal tissues in the primary dentition representing $37 \%$, followed by intrusion with $16.66 \%$, while uncomplicated crown fractures were the most prevalent injury in the permanent dentition with $30.43 \%$, followed by subluxation with $11.11 \%$. Uncomplicated crown fractures, crown root fractures, and middle third root fractures occurred only in permanent teeth (Table 4).

Mucous lesions accounted for $48.1 \%$, with lacerations were $77.8 \%$, contusions were $15.9 \%$, and abrasions were $6.3 \%$. 
Table 2. Distribution of location and etiological factors of TDI according to age

\begin{tabular}{|c|c|c|c|c|c|c|}
\hline & $\leq 3$ years & 3-6 years & $6-9$ years & 9-12 years & $12-15$ years & $\mathbf{p}$ \\
\hline & n (\%) & n (\%) & n (\%) & n (\%) & n (\%) & \\
\hline \multicolumn{7}{|l|}{ Location of trauma } \\
\hline Street & $5(38.5)$ & $3(33.3)$ & $8(38.1)$ & $28(51.8)$ & $18(53)$ & \\
\hline House & $8(61.5)$ & $4(44.4)$ & $7(33.3)$ & 9 (16.7) & $3(8.8)$ & 0.117 \\
\hline School & $0(0)$ & $2(22.2)$ & $4(19)$ & $12(24.1)$ & $9(26.5)$ & \\
\hline Sports hall & $0(0)$ & $0(0)$ & $1(4.8)$ & $1(3.7)$ & $3(8.8)$ & \\
\hline Other places & $0(0)$ & $0(0)$ & $1(4.8)$ & $1(3.7)$ & $1(2.9)$ & \\
\hline \multicolumn{7}{|l|}{ Etiologies } \\
\hline Falls & $11(84.6)$ & $4(44.4)$ & $17(80.9)$ & $34(63)$ & $12(35.3)$ & \\
\hline Road accidents & $1(7.7)$ & $3(33.3)$ & $1(4.8)$ & $10(18.5)$ & $9(26.5)$ & \\
\hline Violence/brawls & $1(7.7)$ & $1(11.1)$ & $1(9.5)$ & $10(18.5)$ & $9(26.5)$ & 0.004 \\
\hline Sport & $0(0)$ & $0(0)$ & $0(0)$ & $0(0)$ & $4(11.7)$ & \\
\hline Others & $0(0)$ & $1(11.1)$ & $1(4.8)$ & $0(0)$ & $0(0)$ & \\
\hline Total & $13(100)$ & $9(100)$ & $21(100)$ & $54(100)$ & $34(100)$ & \\
\hline
\end{tabular}

Table 3. Distribution by type of traumatized teeth

\begin{tabular}{|l|c|c|}
\hline Type of permanent & Mature teeth & Immature teeth \\
\hline traumatized teeth & $\mathbf{n}(\%)$ & $\mathbf{n}(\%)$ \\
\hline Upper central incisor & $102(73.38)$ & $37(69.81)$ \\
\hline Upper lateral incisor & $19(13.66)$ & $5(9.43)$ \\
\hline Lower central incisor & $13(9.35)$ & $6(11.32)$ \\
\hline Lower lateral incisor & $5(3.59)$ & $4(7.54)$ \\
\hline Upper canine & $0(0)$ & $1(1.88)$ \\
\hline Total & $139(100)$ & $53(100)$ \\
\hline
\end{tabular}

The distribution according to age, sex and etiology is shown in Table 5.

Concerning the patients' emergency care, 6 out of 11 were able to recover the avulsed tooth, and all kept it in milk; they were advised by a relative or by a dentist via telephone contact, the remaining 5 patients lost their avulsed tooth and consulted SCUD within an hour or even 6 hours following the occurrence of trauma. Regarding the 77 cases with crown fracture accompanied with loss of tooth substance, only $9(11.7 \%)$ were able to recover the crown fragment(s), the latter were preserved in water in 4 cases $(44.4 \%)$, in milk in 3 (33.3\%) cases, and dry in 2 cases (22.2\%).

\section{Discussion}

The total number of children who visited the hospital due to dental trauma over a 3-month period was 131 (18.1\%) of the 725 who consulted for a dental emergency.

In Croatia, over a 4-year period, 447 patients were received in dental emergency department.[11] In the Kingdom of Saudi Arabia, the study carried out on the children who visited the Pediatric Dental Clinics, at the College of Dentistry, from January 2016 to June 2016 among 868 children aged 3 to 13 years showed a prevalence of $9.79 \%$ of TDI.[12]

Differences in the prevalence of dental trauma between countries can be linked to several factors, such as the type and setting of the study, the age groups involved, the composition of the sample, and behavioral and geographic differences.

The drives behind the large proportion of our pediatric consulting population can be explained by the fact that the SCUD is the only public structure reserved for dental emergencies, it operates even on weekends and holidays, and the survey period coincided in part with school holidays.

The reasons behind limiting our study only on urban population can be explained by the lack of knowledge and the difficulty of access to the rural population as well as by the vulnerability of the urban population to the public road accident risks and sports activities. Our case goes in parallel with the results found in Yemen[13] and in Cameroon.[14]

For the primary dentition, the frequency peak of the encountered trauma is located before the age of 3 years which is a period of walking acquisition and the environment exploration, this is the age of "trip and fall" the toddler age. This is in accordance with earlier study where peaks of TDI in preschool children have been shown at 3 years of age.[15] Odersjö et al[16] found that the highest incidence of trauma occurred at 12-17 months of age. This difference may rely on the study design and in differences in classifying age groups. 
Table 4. Distribution of TDI according to the type of denture

\begin{tabular}{|c|c|c|c|c|}
\hline \multirow[t]{2}{*}{ Types of trauma } & \multicolumn{2}{|c|}{ Permanent dentition } & \multicolumn{2}{|c|}{ Primary dentition } \\
\hline & $\mathbf{n}$ & $\%$ & $\mathbf{n}$ & $\%$ \\
\hline \multicolumn{5}{|l|}{ Hard tissue trauma } \\
\hline Cracks & 6 & 2.9 & 0 & 0 \\
\hline Enamel fractures & 16 & 7.72 & 4 & 7.4 \\
\hline Enamel and Dentin Fractures & 63 & 30.43 & 0 & 0 \\
\hline Complicated Crown Fractures & 19 & 9.17 & 4 & 7.4 \\
\hline Uncomplicated Crown-Root Fracture & 11 & 5.31 & 0 & 0 \\
\hline Complicated Crown-Root Fracture & 8 & 3.86 & 4 & 7.4 \\
\hline Root fracture in the cervical third & 5 & 2.41 & 2 & 3.7 \\
\hline Root fracture in the middle third & 2 & 0.96 & 0 & 0 \\
\hline \multicolumn{5}{|l|}{ Periodontal trauma } \\
\hline Concussion & 4 & 1.93 & 0 & 0 \\
\hline Subluxation & 23 & 11.11 & 1 & 1.85 \\
\hline Extrusion & 7 & 3.38 & 4 & 7.4 \\
\hline Lateral luxation & 15 & 7.24 & 6 & 11.11 \\
\hline Intrusion & 12 & 5.79 & 9 & 16.66 \\
\hline Avulsion & 11 & 5.31 & 20 & 37.03 \\
\hline Alveolar trauma & 4 & 1.93 & 0 & 0 \\
\hline Bone trauma & 1 & 0.48 & 0 & 0 \\
\hline Total & 207 & 100 & 54 & 100 \\
\hline
\end{tabular}

Table 5. Distribution of TDI by age group, sex and etiology of trauma

\begin{tabular}{|c|c|c|c|c|c|c|c|c|}
\hline \multirow{3}{*}{$\begin{array}{l}\text { Types of trauma } \\
\text { Groups' Age }\end{array}$} & \multirow{2}{*}{\multicolumn{2}{|c|}{$\begin{array}{c}\text { Hard tissues trauma } \\
\mathbf{n}(\%) \mathbf{p}\end{array}$}} & \multirow{2}{*}{\multicolumn{2}{|c|}{$\begin{array}{c}\text { Periodontal trauma } \\
\mathbf{n}(\%) \mathbf{p} \\
\end{array}$}} & \multirow{2}{*}{\multicolumn{2}{|c|}{$\begin{array}{c}\text { Alveolar trauma } \\
\mathbf{n}(\%) \mathbf{p} \\
\end{array}$}} & \multirow{2}{*}{\multicolumn{2}{|c|}{$\begin{array}{c}\text { Bone trauma } \\
\mathrm{n}(\%) \mathrm{p}\end{array}$}} \\
\hline & & & & & & & & \\
\hline & & \multirow{6}{*}{$\mathrm{p} 0.03$} & & & & & & \\
\hline$\leq$ to 3 years & $9(6.25)$ & & 18 (16.07) & \multirow{5}{*}{$p 0.01$} & $0(0)$ & \multirow{5}{*}{$p 0.245$} & $0(0)$ & \multirow{5}{*}{ p 0.838} \\
\hline $3-6$ years & $3(2.08)$ & & $12(10.71)$ & & $0(0)$ & & $0(0)$ & \\
\hline $6-9$ years & $16(11.11)$ & & 30 (26.78) & & $0(0)$ & & $0(0)$ & \\
\hline $9-12$ years & $76(52.77)$ & & $21(18.75)$ & & $1(25)$ & & $1(100)$ & \\
\hline $12-15$ years & $40(27.77)$ & & $31(27.67)$ & & $3(75)$ & & $0(0)$ & \\
\hline \multicolumn{9}{|l|}{ Gender } \\
\hline Male & 109 (75.69) & \multirow{2}{*}{ p 0.521} & 75 (66.96) & \multirow{2}{*}{ p 0.327} & $3(75)$ & \multirow{2}{*}{ p 0.110} & $0(0)$ & \multirow{2}{*}{ p 0.884} \\
\hline Female & $35(24.30)$ & & $37(33.03)$ & & $1(25)$ & & $1(100)$ & \\
\hline \multicolumn{9}{|l|}{ Etiological factors } \\
\hline Falls & $81(56.25)$ & \multirow{5}{*}{$p 0.643$} & $61(54.46)$ & \multirow{5}{*}{ p 0.832} & $0(0)$ & \multirow{5}{*}{ p 0.022} & $0(0)$ & \multirow{5}{*}{ p 0.316} \\
\hline Road accidents & $28(19.44)$ & & $23(20.53)$ & & $2(50)$ & & $0(0)$ & \\
\hline Violence/brawls & $27(18.75)$ & & $23(20.53)$ & & $1(25)$ & & $1(100)$ & \\
\hline Sport & $8(5.55)$ & & $2(1.78)$ & & $1(25)$ & & $0(0)$ & \\
\hline Others & $0(0)$ & & $3(2.67)$ & & $0(0)$ & & $0(0)$ & \\
\hline Total & \multicolumn{2}{|c|}{$144(100)$} & \multicolumn{2}{|c|}{$112(100)$} & \multicolumn{2}{|c|}{$4(100)$} & \multicolumn{2}{|c|}{$1(100)$} \\
\hline
\end{tabular}

For the permanent dentition, the frequency peak is between 9 and 12 years which may be attributed to the fact that older children and pre adolescents have a more intense activity and are more inattentive compared to adolescents and are more on their own compared to younger children, supporting the findings of other 
authors such as Navabazam and Farahani[17] (peak is between 9 and 10 years) and Gark et al[18] who found that children aged 9-14 years were at 1.18 times greater risk of having TDIs compared to children aged 7-8 years, and Alhaddad et al[19] who found that the incidence of dental trauma peaked at 9 years of age.

Trauma affects two and a half times more males than females; this can be attributed to the more energetic and aggressive games that boys play. Several studies have found this difference.[18,20,21]

This masculine predominance seems to diminish for children aged less than 3 years old. Such age is characterized by the first steps and the discovery of the surrounding. This concerns both sexes without distinction. The Male/Female ratio was 1.6 before 3 years old and was 2.7 after 3 years old.

The time elapsed between injury and referral to the hospital is a crucial factor since it will condition the prognosis and guide the therapeutic decision. The shorter it is, the better the chances of recovery are achievable. Our study has revealed that the rate of $36.6 \%$ represents patients consulting on the day of the traumatic event. This significant rate can be attributed to the parents' apprehension of dental trauma and their knowledge about the existence of the Dental Emergency Service, which has been inaugurated since 2000.

In Croatia, a rate of $40 \%$ of patients consulting on the same day of the trauma was reported.[11] However, the delay in consultation is still to be deplored. Patients consulting between the 1 st and the 7 th day represent $27.5 \%$, and those consulting beyond this date represent $36 \%$. This prejudicial delay may be due to some parent's ignorance about the trauma complications, the absence of serious signs, the lack of home emergency procedures awareness, the difficulty of access to care, and sometimes parental abuse may prevent immediate consultation because of mistrust.

Among the $40.4 \%$ of patients who did not consult the SCUD directly, $26.7 \%$ consulted a specialist doctor. This can be explained by the presence of associated lesions such as general lesions (as head trauma), extraoral lesions (upper lip lesion, cheek or chin lesion) which leads patients to spontaneously present themselves at the otorhinolaryngology emergency departments, for example.

Concerning the $13.7 \%$ consulting a private dentist who did not proceed the right management care, apprehension regarding the care of the traumatized child and lack of equipment and/or radiography were reported by the parents as being involved. These shortcomings have also been noted in several studies, including a systematic review conducted by Yeng and Parashos in Australia.[22]

It is therefore necessary to improve practitioners knowledge in the treatment of traumatic emergencies and to encourage postgraduate training in the child trauma field. TDI is a real public health problem that can expose children to long complications and costly treatments.

According to companions, among children aged over 6 years, most traumatisms occur in the street. This observation can be justified by the time boys generally spend on the street and is also caused by parental carelessness regarding their children's safety. This result is consistent with that found by Kirzioglu in Turkey.[23] Among children under 6 years of age, trauma most often occurs in the family environment, which matches the findings of several studies. $[8,15,16]$

Falls which show children's inattention are at the top of the list of traumas etiologies followed by public road accidents linked to children's carelessness and road insecurity, particularly in the large city of Casablanca. Also, violence/brawls are not negligible, as they can arise from domestic abuse, delinquency, etc. Falls were the main factors of dental injuries among the patients in many studies.[15,24,25]

Trauma affecting two teeth is more frequent (43.5\%) than that affecting one tooth (39\%). This could be related to the large volume of the object impact which increases the contact surface with the crowns (falls have been the most frequent) or to the maxillary proalveolus which has been well observed without being recorded. These observations are confirmed by Costa et al in Brazil 39.6\% for trauma affecting two teeth[26] and by Škaričić et al in Croatia (66.7\%).[11]

The upper central incisors are the most affected due to their location and volume. The traumas of the supporting tissues, which are represented primarily by avulsions followed by subluxations then by intrusions, concern more the primary or immature permanent teeth. This observation is coherent considering the plasticity of the periodontal structures, whereas the traumas of the hard tissues, which is represented primarily by the simple crown fractures, are more frequent in mature permanent teeth. Several studies confirm these results.[11,27]

Concerning the management of trauma, 5 avulsed teeth within a total of 11 were lost along with the coronal fragments, of which only 9 out of a total of 77 were recovered at the site of the trauma. This is partly caused by the parents' lack of information as to the interest of keeping the avulsed tooth or coronal fragment in improving the prognosis in the short and medium term. 
The results obtained in this study remain specific and not necessarily representative of Moroccan population. It would be interesting to conduct similar studies in various social contexts (multicenter, liberal practice) to obtain more enriched data on dental trauma regarding Moroccan children. These will be useful for the implementation of effective prevention programs.

\section{Conclusion}

This work has allowed us to highlight a prevalence of $18.1 \%$ of patients ranged 6 months to 15 years of age sought emergency attention by dental trauma at a Casablanca public dental emergency department. Most of these children are from a modest socioeconomic level (92.4\%). We found that males showed a higher frequency $(71.8 \%)$ of dental trauma than females. The largest age group with dental trauma (41.2\%) corresponded to the 9-12 years old. The street was the most common location where dental injuries occurred (47.3\%). The most common types of injury in the primary dentition were avulsion (37\%), while in the permanent dentition, it was uncomplicated crown fractures $(30.43 \%)$. Patients who consulted the same day were of the order of $36.6 \%$.

The implementation of a prevention and information policy in a participatory approach is essential.[28] Parents, caregivers, teaching staff, and others working with youth need to be knowledgeable about Traumatic dental injuries management and understand the importance of evaluation by a dentist as soon as possible after the incident. Concerning liberal practitioners and public dentists, training cycles in dental trauma will help them to better serve the local population.

Financial Disclosure: Nil.

Conflict of Interest: None declared.

\section{References}

1. Cagetti MG, Marcoli PA, Berengo M, et al. Italian guidelines for the prevention and management of dental trauma in children. Ital J Pediatr 2019;45(1):157 doi:10.1186/s13052-019-0734-7

2. Richards D. One billion people have experienced a traumatic dental injury. Evid Based Dent 2018;19(2):34-35 doi:10.1038/ sj.ebd.6401297

3. Lam R. Epidemiology and outcomes of traumatic dental injuries: a review of the literature. Aust Dent J 2016;61 Suppl 1:4-20 doi:10.1111/adj.12395

4. Bratteberg M, Thelen DS, Klock KS, Bårdsen A. Traumatic dental injuries-prevalence and severity among 16-year-old pupils in western Norway. Dent Traumatol 2018;34(3):144-150 doi:10.1111/edt.12399
5. Abreu MGL, Milani AJ, Fernandes TO, Gomes CC, Antunes LS, Antunes LAA. Dental trauma in primary dentition, its effect on permanent successors and on Oral Health-Related Quality of Life: a 4-year follow-up case report. Int J Burns Trauma 2020;10(5):201-209

6. Soares FC, Cardoso M, Bolan M. Association between trauma to primary incisors and crown alterations in permanent successors. Braz Dent J 2014;25(4):332-335 doi:10.1590/01036440201300057

7. Borges TS, Vargas-Ferreira F, Kramer PF, Feldens CA. Impact of traumatic dental injuries on oral health-related quality of life of preschool children: A systematic review and meta-analysis. PLoS One 2017;12(2):e0172235 doi:10.1371/journal.pone.0172235

8. Day PF, Flores MT, O'Connell AC, et al. International Association of Dental Traumatology guidelines for the management of traumatic dental injuries: 3. Injuries in the primary dentition. Dent Traumatol 2020;36(4):343-359 doi:10.1111/edt.12576

9. Levin L, Day PF, Hicks L, et al. International association of dental traumatology guidelines for the management of traumatic dental injuries: General introduction. Dent Traumatol 2020;36(4):309313 doi:10.1111/edt.12574

10. Andreasen JO, Andreasen FM, Andersson L. Textbook and color atlas of traumatic injuries to the teeth. 4 th ed. Oxford, UK: WileyBlackwell; 2007

11. Škaričić J, Vuletić $M$, Hrvatin S, Jeličić J, Čuković-Bagić I, Jurić $\mathrm{H}$. Prevalence, type and etiology of dental and soft tissue injuries in children in Croatia. Acta Clin Croat 2016;55(2):209-216 doi:10.20471/acc.2016.55.02.05

12. Gupta M, Apathsakayan R, Abhishek A. Traumatic injuries to the anterior teeth among children of Jazan, Kingdom of Saudi Arabia: A screening study. World J Dent 2018;9(3):192-196

13. AL-Jawfi KA. Prevalence of traumatized permanent incisors among Yemeni children. IJDR 2018;6(1):25-28 doi:10.14419/ijdr. v6i1.9325

14. Azodo CC, Agbor MA. Prevalence and unmet treatment need of traumatized incisor among Cameroonian schoolchildren in North West Province. Odontostomatol Trop 2015;38(152):33-38

15. Oldin A, Lundgren J, Nilsson M, Norén JG, Robertson A. Traumatic dental injuries among children aged 0-17 years in the BITA study - a longitudinal Swedish multicenter study. Dent Traumatol 2015;31(1):9-17 doi:10.1111/edt.12125

16. Odersjö ML, Robertson A, Koch G. Incidence of dental traumatic injuries in children 0-4 years of age: a prospective study based on parental reporting. Eur Arch Paediatr Dent 2018;19(2):107-111 doi:10.1007/s40368-018-0334-z

17. Navabazam A, Farahani SS. Prevalence of traumatic injuries to maxillary permanent teeth in 9- to 14-year-old school children in Yazd, Iran. Dent Traumatol 2010;26(2):154-157 doi:10.1111/ j.1600-9657.2009.00861.x

18. Garg K, Kalra N, Tyagi R, Khatri A, Panwar G. An Appraisal of the Prevalence and Attributes of Traumatic Dental Injuries in the Permanent Anterior Teeth among 7-14-Year-Old School Children of North East Delhi. Contemp Clin Dent 2017;8(2):218224 doi:10.4103/ccd.ccd_133_17 
19. Alhaddad B, Rózsa NK, Tarján I. Dental trauma in children in Budapest. A retrospective study. Eur J Paediatr Dent 2019;20(2):111-115 doi:10.23804/ejpd.2019.20.02.05

20. Tewari N, Mathur VP, Siddiqui I, Morankar R, Verma AR, Pandey RM. Prevalence of traumatic dental injuries in India: A systematic review and meta-analysis. Indian J Dent Res 2020;31(4):601-614 doi:10.4103/ijdr.IJDR_953_19

21. Zaleckiene V, Peciuliene V, Brukiene V, Drukteinis S. Traumatic dental injuries: etiology, prevalence and possible outcomes. Stomatologija 2014;16(1):7-14

22. Yeng T, Parashos P. Dentists' management of dental injuries and dental trauma in Australia: a review. Dent Traumatol 2008;24(3):268-271 doi:10.1111/j.1600-9657.2007.00543.x

23. Kırzıoglu Z, Oz E. Changes in the aetiological factors of dental trauma in children over time: An 18-year retrospective study. Dent Traumatol 2019;35(4-5):259-267 doi:10.1111/edt.12478

24. Rouhani A, Movahhed T, Ghoddusi J, Mohiti Y, Banihashemi E, Akbari M. Anterior traumatic dental injuries in East Iranian school children: prevalence and risk factors. Iran Endod J 2015;10(1):35-38

25. Chopra A, Lakhanpal M, Rao N, Gupta N, Vashisth S. Traumatic dental injuries among 12-15-year-old-school children in Panchkula. Arch Trauma Res 2014;3(1):e18127 doi:10.5812/ atr.18127

26. Costa VP, Bertoldi AD, Baldissera EZ, Goettems ML, Correa MB, Torriani DD. Traumatic dental injuries in primary teeth: severity and related factors observed at a specialist treatment centre in Brazil. Eur Arch Paediatr Dent 2014;15(2):83-88 doi:10.1007/ s40368-013-0068-x

27. Gokcek M, Durmuslar S, Kokturk F. Retrospective analysis of traumatic dental injuries in the western black sea region of Turkey. Niger J Clin Pract 2020;23(1):84-90 doi:10.4103/njcp. njcp_230_190

28. Dhaimy S, Assakhen I, Lahlou K, Hamza M, Rifki C. Knowledge of Moroccan dentists about the management of dental hard tissues trauma. OHDM 2017;16(5);1-7 